\title{
Lymphangioma of the Tongue Revisited
}

\author{
Ahmed Hassan Kamil Mustafa, MSC, FFDRCSI*
}

Department of Maxillofacial Surgery and Diagnostic Sciences-College of Dentistry, King Saud Bin Abdulaziz University for Health Sciences, Riyadh, Saudi Arabia

*Corresponding author: Department of Maxillofacial Surgery and Diagnostic Sciences-College of Dentistry, King Saud Bin Abdulaziz University for Health Sciences, Riyadh, Saudi Arabia, Tel: 00966504767135

\begin{abstract}
Lymphangioma is a benign, congenital hamartomatous malformation of the lymphatic system, it is more common in the head and neck region. Oral lymphangiomas are rare but if it occurs, the tongue is the most commonly affected site, rarely on other sites such as the palate, gingiva, and alveolar ridge of the mandible. This study aims to throw light on lymphangioma of the tongue regarding pathogenesis, clinical signs and symptoms, and the different treatment modalities. Although lymphangioma is benign and its occurrence in the tongue extremely rare, a health care provider like a dentist must be conscious of the existence of such lesion to promote a precise diagnosis, and therefore, proper treatment can be rendered for this disorder, to avoid the serious complications that might occur when it becomes traumatized tor infected in which case it obstructs the airway and lead to the death of the patient if not promptly rescued.
\end{abstract}

\section{Introduction}

Lymphangioma is benign tumors involving lymphatic channels the majority are confined to the head and neck region in about the majority of cases [1]. Lymphangiomas occur commonly at birth or before the age of two [2]. In the oral cavity, the anterior two-thirds of the tongue is the most commonly involved site [3]. This study aims to throw light on lymphangiomas of the tongue regarding pathogenesis, clinical signs and symptoms, classification, and the different treatment modalities.

\section{Materials and Methods}

An electronic search of the databases was conducted, within PubMed, using a combination of keywords and control terms (MeSH) were used wherever possible. The search terms included lymphangioma and oral cavity, lymphangioma and tongue, lymphatic malformations, and tongue.

\section{Literature review}

Lymphangioma is a benign, congenital hamartomatous malformation of the lymphatic system; it is more common in the head and neck region [2]. It arises as a result of hyperplasia of sequestered lymphatic vessels that have lost connection with the rest of the lymphatic channels. Virchow was the first to describe lymphangioma in 1854 [2]. Lymphangioma has a high for the head and region with about $75 \%$ occurring at this site. $50 \%$ of lymphangiomas are present at birth and $90 \%$ develop by 2 years of age [2]. The tongue is the most commonly affected site in the oral cavity, rarely on other sites such as the palate, gingiva, and alveolar ridge of the mandible [4]. Lymphangiomas usually present as papillary lesions with the same colour as adjacent mucosa [5]. Occasionally oral lymphangiomas are associated with syndromes like Turner's syndrome, Noonan's syndrome, trisomies, cardiac anomalies, fetal hydrops, fetal alcohol syndrome, and Familial pterygium colli [6]. Tongue lymphangiomas are usually superficial with a pebbly surface resembling a cluster of translucent vesicles [7]. The anterior two-thirds of the tongue is the most commonly affected site causing enlargement of the tongue [7]. Patients with tongue lymphangioma tend to have speech disturbances, poor oral hygiene, and bleeding from the tongue associated with trauma [8].

The complications of lymphangioma affect the patients in many ways including aesthetic, occlusal, functional, and psychological aspects [9]. The most serious complications are those related to infection which can result in Ludwig's angina associated with

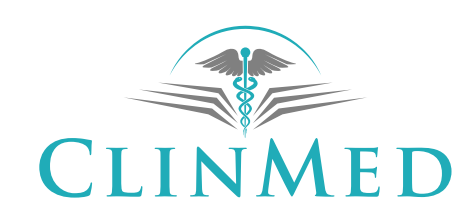

INTERNATIONAL LIBRARY

Citation: Mustafa AHK (2021) Lymphangioma of the Tongue Revisited. Res Rep Oral Maxillofac Surg 5:059. doi.org/10.23937/2643-3907/1710059

Accepted: October 06, 2021; Published: October 08, 2021

Copyright: (c) 2021 Mustafa AHK. This is an open-access article distributed under the terms of the Creative Commons Attribution License, which permits unrestricted use, distribution, and reproduction in any medium, provided the original author and source are credited. 
an infected base of the tongue lymphangioma [10]. Postoperative complications include seroma formation, infections, minor bleeding, recurrent cellulitis, and lymph fluid leakage [11].

Lymphangiomas have been classified into:

- LymphangiomaSimplex(CapillaryLymphangioma) consists of small, capillary sized vessels.

- Cavernous Lymphangioma is composed of large, dilated lymphatic vessels.

- Cystic Lymphangioma (Cystic Hygroma) exhibits large macroscopic cystic spaces [12].

Lymphangiomas are characterized histologically by the formation of lymphatic channels lined by endothelial cells, often the three types may be seen at the same lesion. The most common of the three types is the cavernous lymphangioma and is seen commonly in the tongue and floor of the mouth [13].

Another classification of the lymphangioma of head and neck based on the anatomical involvement had been proposed by De SerresLM.

- Stage/class I-infrahyoid unilateral lesions;

- Stage/class II-suprahyoid bilateral lesions;

- Stage/class III-suprahyoid or infrahyoid unilateral lesions;

- Stage/class IV-suprahyoid bilateral lesions;

- Stage/class V-suprahyoid or infrahyoid bilateral lesions;

- Stage/class IV-infrahyoid bilateral lesions [14].

According to their clinical presentation lymphangiomas are classified into macrocystic (cavities larger than about $2 \mathrm{~cm}^{3}$ ), microcystic (cavities smaller than about 2 $\mathrm{cm}^{3}$ ), and mixed (combining these two types). The objectives of the treatment of lymphangiomatous macroglossia.

The differential diagnosis for lymphangioma includes haemangioma, congenital hypothyroidism, Amyloidosis, Neurofibromatosis, Primary muscular hypertrophy [15].

The treatment of lymphangioma depends upon their type, size, the involvement of anatomical structures, and infiltration to the surrounding tissues.

Different treatment modalities have been tried for the management of lymphangiomas such as laser therapy, cryotherapy, embolization, and electrocautery. Various types of sclerosing agents have been used for the treatment of lymphangiomas including that affecting the tongue, bleomycin, and OK432. OK432 is a lyophilized mixture of streptococcus pyogenes and penicillin $\mathrm{G}$ potassium is considered as the first line of treatment of lymphangiomas because of the absence of perilesional fibrosis when using OK432 [16]. The sclerosing agent OK-432 is effective for macrocystic lymphatic malformations but showed less promise for microcystic lesions, mixed lesions, and lesions outside the head and neck region $[8,17]$.

The after-effects of sclerosing agents include fever and swelling at the site of injection [16]. Because of the high fluid content in the tissues and poor blood supply, cryosurgery has also been tried for treating lymphangiomas [4]. Laser photocoagulation has been reported useful in controlling the tongue size and removing superficial lymphangioma in some cases [18]. Surgical excision is the ultimate choice of treatment for lymphangiomas. Surgical excision is preferred as spontaneous regression of lymphangiomas is rare [2] and most of the adult lymphangiomas are encapsulated or partially circumscribed [16].

\section{Conclusion}

Although lymphangioma is benign and its occurrence in the tongue extremely rare, a health care provider like a dentist must be conscious of the existence of such lesion to promote a precise diagnosis, and therefore, proper treatment can be rendered for this disorder, to avoid the serious complications that might occur when it becomes traumatized tor infected in which case it obstructs the airway and lead to the death of the patient if not promptly rescued.

\section{Conflict of Interest}

None declared.

\section{Ethical Approval}

Not applicable.

\section{References}

1. Dogan N, Durmaz CE, Sencimen M, Ucok O, Okcu KM, et al. (2010) The treatment of recurrent lymphangioma in the oral mucosa by cryosurgery. Oral Health and Dent Manag Black Sea Count 9: 7.

2. Kheur SM, Routray S, Ingale Y, Desai R (2011) Lymphangioma of the tongue: A rare entity. Indian J Dent Adv 3: 635-637.

3. Stanescu L, Georgescu EF, Simionescu C, Georgescu I (2006) Lymphangioma of the oral cavity. Romanian Journal of Morphology and Embryology 47: 373-377.

4. Vasconcelos MG, Santos BC, Lemos LCP, Ribeiro BF, Iglesias DP, et al. (2011) Oral lymphangioma: Case report. Rev Sul-Bras Odontol 8: 352-356.

5. Yoganna SS, Rajendra Prasad RG, Sekar B (2014) Oral lymphangioma of the buccal mucosa a rare case report. Journal of Pharmacy \& Bio allied Sciences 6: S188-S189.

6. Rathan JJ, Harsha Vardhan BG, Muthu MS, Venkatachalapathy, Saraswathy K, et al. (2005) Oral lymphangioma: A case report. J Indian Soc Pedod Prev Dent 23: 185-189.

7. Neville, Damn, Allen, Bouquot (2009) Oral and Maxillofacial Pathology. ( $3^{\text {rd }}$ edn) Soft tissue tumours. Elsevier 547-549.

8. Brennan TD, Miller AS, Chen S (1997) Lymphangiomas of the oral cavity: A clinicopathologic, immunohistochemical, 
and electron microscopic study. J Oral Maxillofac Surg 55: 932-935.

9. Guelmann M, Katz J (2003) Macroglossia combined with lymphangioma: A case report. J Clin Pediatr Dent 27: 167170.

10. Uguru C, Edafioghor F, Uguru N (2011) Lymphangioma of the tongue with macroglossia: A case report. Niger $\mathrm{J}$ Med 20: $166-168$

11. Tasca RA, Myatt HM, Beckenham EJ (1999) Lymphangioma of the tongue presenting as Ludwig's angina. Int J Pediatr Otorhinolaryngol 51: 201-205.

12. Hancock BJ, St Vil D, Luks FI, Di Lorenzo M, Blanchard H (1992) Complications of lymphangiomas in children. J Pediatr Surg 27: 220-224.

13. Devi SI, Gupta MK, Durga Prasad KVN, Shankar T, Majid J (2014) Lymphangioma of the soft palate: a case report. J of Evolution of Med and Dent Sci 3: 13607.
14. Bindhu PR, Mathew J, Thomas $P$, Jayanthi $P$, Krishnapillai R (2013) Cavernous lymphangioma of the lower lip. Health Sciences 2: 1-7.

15. De Queiroz AM, Silva RA, Margate LC, Nelson FP (2006) Dental care management of a young patient with extensive lymphangioma of the tongue: A case report. Spec Care Dentist 26: 20-24.

16. Martin SG, Michael G, Jonathan AS (2008) Burket's Oral Medicine. (11 th edn), Hamilton: BC Decker Inc 139-141.

17. Yaita T, Onodera K, Xu H, Ooya K (2007) Histomorphometrical study in cavernous lymphangioma of the tongue. Oral Dis 13: 99-104.

18. Usha V, Sivasankari T, Jeelani S, Asokan GS, Parthiban J (2014) Lymphangioma of the Tongue - A Case Report and Review of Literature. Journal of Clinical and Diagnostic Research 8: ZD12-ZD14. 